\title{
INCIDENCE, CAUSES AND MANAGEMENT OF RETAINED PLACENTA OF ADMITTED CASES IN IN- PATIENT DEPARTMENT OF DHAKA MEDICAL COLLEGE HOSPITAL
}

\author{
DAS SR ${ }^{1}$, SULTANA ${ }^{2}$, AKHTER $\mathrm{S}^{3}, \mathrm{KHAN} \mathrm{F}^{4}$, WAZED F $^{5}$
}

\begin{abstract}
Retained placenta is a condition in which the placenta is retained for more than half-an hour after the birth of a child. It accounts for 5-10\% of all postpartum haemorrhage (PPH). The present study was conducted to find out the incidence, causes and management of retained placenta of admitted cases in In-Patient Department (IPD) of Obstetrics \& Gynaecology of Dhaka Medical College Hospital, Dhaka during the period from June 01 to December 31, 2003. 163 patients were included in the study who presented with retained placenta and developed retained placenta in IPD who had undergone vaginal delivery, with pregnancy equal to or more than 28 weeks both stillbirths and live-births, both singleton and multiple pregnancy. The incidence of retained placenta was found 3.54\% of total admissions. Retained placenta developed in 1.53\% cases among 1,506 vaginal deliveries in this hospital during this period. The mean age of the respondents was 27.19 1.54 and most of the patients were aged between 21 to 30 years, multipara, illiterate and from low income group and poor socio-economic status. Among them $81.60 \%$ had home delivery, $64.42 \%$ delivered between 37 to 40 weeks of pregnancy. Majority of the patients i.e. $61.96 \%$ reached the hospital within 2 to 6 hours of development of retained placenta and 49.07\% had shock with PPH. About 23.92\% respondents had predisposing factors like $D \& C$, manual removal of $R P$ and caesarean section. A considerable percentage (19.63\%) had history of MR. About 96.93\% respondents required manual removal of retained placenta. 124 (76.07\%) received blood transfusion ranging from 1 to 13 units of blood. The causes of retained placenta were uterine inertia (38.65\%), morbid adhesion (52.76\%) and less expulsive efforts of the patients (7.98\%). Placenta accreta was the major (96.51\%) cause of morbid adhesion. The range of hospital stay was between 6 to 15 days. Of the total retained placenta cases, 98.77\% patients improved and $1.23 \%$ patients died of irreversible shock due to $P P H$.
\end{abstract}

Key words: Retained Placenta, Caesarean Section.

J Dhaka Med Coll. 2009; 18(1) : 20-24

\section{Introduction}

Retained placenta is a condition in which the placenta is retained for more than half-an hour after the birth of a child. ${ }^{1}$ Retained placenta (RP) and its membranes causes 5 to $10 \%$ of all postpartum hemorrhage. ${ }^{2}$ Postpartum hemorrhage $(\mathrm{PPH})$ is a leading cause of maternal death all over the world. ${ }^{3}$ In developing countries, it is responsible for an annual mortality of approximately 150,000 women per year. ${ }^{4}$ It is a direct cause of maternal death and $\mathrm{PPH}$ remains the number 1 killer of mothers and it contributes $26 \%$ of maternal death in Bangladesh. ${ }^{5}$ In Nepal it is as high as $47 \%^{6}$, in Indonesia it is $28 \%$, in India it is $23 \%$, and in Sri Lanka, it is 35\% ${ }^{7}$. The causes of RP are uterine inertia, morbid adhesion of placenta, constriction ring and less expulsive efforts of the patient. ${ }^{8}$ Mismanagement of $3^{\text {rd }}$ stage of labour is one of the causes of uterine inertia leading to $\mathrm{PPH}$ as well as retention of placenta. A $3^{\text {rd }}$ stage of thirty minutes or longer occurred in $3.3 \%$ deliveries. ${ }^{9}$ Fifty Six percent of pregnant mothers receive one ante natal

1. Junior Consultant, Upazilla Health Complex, Rajair, Madaripur.

2. Assistant Professor, Department of Obstetrics \& Gynaecology, Dhaka National Medical College, Dhaka.

3. Professor, Department of Infertility, BSMMU, Dhaka.

4. Junior Consultant, Shaheed Suhrawardy Medical College Hospital, Dhaka.

5. Assistant Professor, Department of Obstetrics \& Gynaecology, Dhaka Medical College, Dhaka.

Correspondence: Dr. SR Das 
checkup, $92 \%$ of deliveries take place at home and only $14 \%$ deliveries are attended by trained personne ${ }^{10}$. About three Bangladeshi women die every hour of complications related to pregnancy and child birth. The Bangladesh Maternal Mortality Survey 2001 indicates a maternal mortality rate of 320 deaths per 100,000 life births in the period 1998 to $2001 .^{11}$ Maternal Mortality Rate (MMR) of a country is globally now considered an indicator of the overall status of women. In Bangladesh, MMR represents the end point in a life time experience of gender discrimination, neglect and deprivation. Besides, the existence of high MMR represents the failure of the health system to effectively provide services and care for the people. ${ }^{12}$ There are only few works done in Bangladesh in the areas of Retained Placenta and its management. It is important to identify the depth of the problem and take measures to reduce its incidence and initiate appropriate, need based timely management of the problem. This study is undertaken to find out the incidence, causes and its management in a tertiary level hospital e.g. $\mathrm{DMCH}$ in Bangladesh during the period from June to December 2003.

\section{Materials and Methods:}

This was a prospective cross sectional study, conducted in the Department of Obstetrics \& Gynaecology, Dhaka Medical College Hospital $(\mathrm{DMCH})$, Dhaka, over the period of June to December, 2003. Patients who presented with retained placenta and developed retained placenta in Inpatient department in the hospital were taken as study unit. Both quantitative and qualitative data were collected. On admission, a detailed history of the illness was taken from the patient, thorough general \& systemic examination was done, and findings of the performed investigations were recorded, relevant associated medical conditions were recorded carefully, operative findings and preoperative complications were recorded and noted from hospital records from patients' file.

\section{Results:}

The mean age of the respondents was 27.19 years with range 18 to 41 years. Out of 163 respondents, $33.74 \%$ were found at the age group of 26-30 years and $6.74 \%$ were found at the age group of $36-40$ years. Regarding the socio-economic conditions of the families $71.17 \%$ families had monthly income less than Taka 3,000/- and 4.29\% families had monthly income more than Taka 6,000/-. Among the respondents $55.83 \%$ were of para 2 or 3 . Most of the deliveries (Fig. 1) $81.60 \%$ were conducted delivery at home by the Dai (female birth attendant) or relatives, $14.29 \%$ by doctors at $\mathrm{DMCH}$ and $4.29 \%$ by medical persons at clinics or hospitals outside.

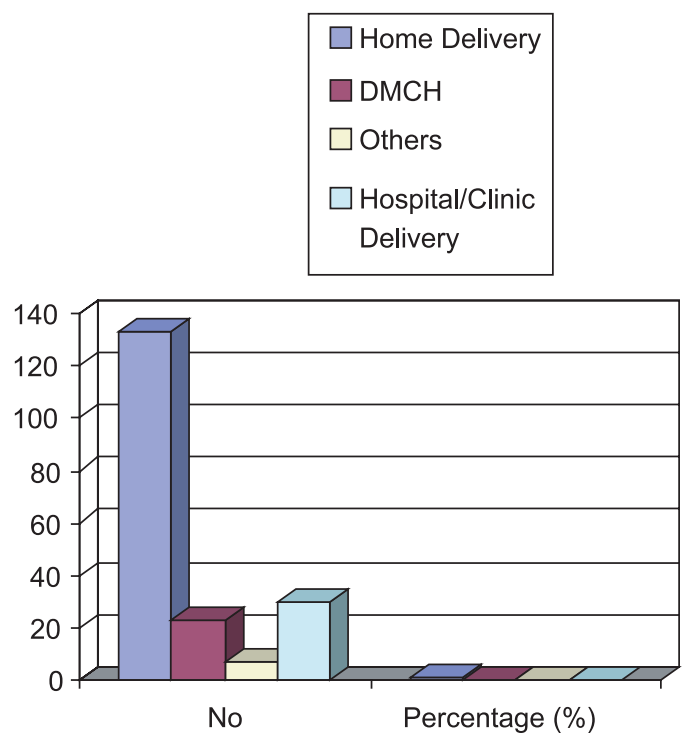

Fig.-1: Frequency distribution of the place of delivery of the last baby $(n=163)$.

Majority i.e. $61.96 \%$ of the respondents were admitted between 2 to 6 hours after developing retained placenta and $1.23 \%$ were admitted after 24 hours. Minimum delivery-admission interval was 40 minutes and maximum was 31 hours. About $20 \%$ of the respondents had history of MR; $17.79 \%$ had history of D \& C, $4.29 \%$ had history of manual removal of RP and $1.84 \%$ had history of caesarian section. Regarding clinical presentations, $49.07 \%$ presented with shock and PPH and $1.23 \%$ had shock without PPH. Associated complications with retained placenta were perineal tear (4.29\%), sepsis $(3.68 \%)$ and vaginal tear, cervical tear and uterine prolapse $(1.80 \%)$, acute inversion of uterus (1.23\%). 
Table-I

Type of management regarding removal of $R P$ among study respondents $(n=163)$

\begin{tabular}{lcc}
\hline Type of Management & No & Percentage (\%) \\
\hline A. Conservative: & 4 & $2.45 \%$ \\
- Inj. Oxytocin & 1 & $0.61 \%$ \\
- Inj. Oxytocin \& CCT & 3 & $1.80 \%$ \\
B. Surgical: & 159 & $97.54 \%$ \\
- Manual removal & 158 & $96.93 \%$ \\
- Hysterotomy & 1 & $0.61 \%$ \\
\hline Total & 163 & $100 \%$ \\
\hline
\end{tabular}

Regarding management $96.93 \%$ of the respondents needed manual removal of placenta (Table-II), 2.45\% were managed conservatively and $0.61 \%$ needed hysterotomy. On the other hand $2.45 \%$ treated with oxytocin drip and controlled cord traction. Average 1.48 unit of blood was transfused per patient, $39.26 \%$ of the respondents received 1 unit of blood and $23.93 \%$ required no blood transfusion. Requirement of blood transfusion ranged between 1 to 13 units.

Percentage (\%)
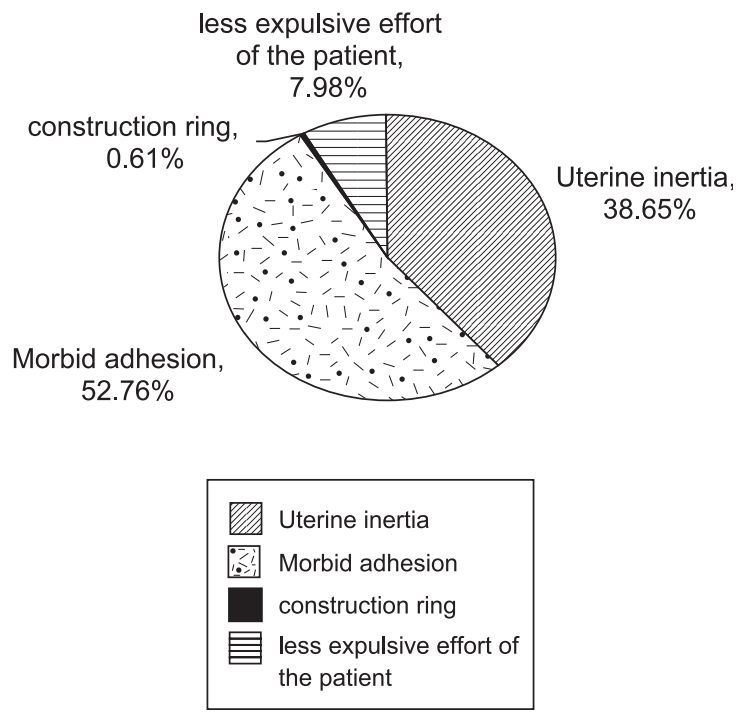

Fig. -2: Frequency of causes of retained placenta $(n=163)$.

Regarding the causes of retained placenta $52.76 \%$ were due to morbid adhesion (Fig -2), $7.98 \%$ were due to less expulsive efforts of the patients and only one case $(0.61 \%)$ due to constriction ring. Uterine inertia was the second most common cause of RP 63 (38.65\%). The types of morbid adhesion of placenta were placenta accreta $(96.51 \%)$, placenta increta $(3.49 \%)$ and there was no case of placenta percreta. About 6.13\% developed PPH, 2.45\% developed sepsis/Endometritis and $0.61 \%$ developed perforation of uterus at or after manual removal of placenta.

Table-II

Length of hospital stay by study respondents $(n=163)$

\begin{tabular}{lcc}
\hline Length of hospital stay & No & Percentage (\%) \\
\hline Less than 1 day or 1 day & 72 & $44.17 \%$ \\
2 to 4 days & 65 & $39.88 \%$ \\
5 to 7 days & 17 & $10.43 \%$ \\
8 to 10 days & 7 & $4.29 \%$ \\
More than 10 days & 2 & $1.23 \%$ \\
\hline Total & 163 & $100 \%$ \\
\hline
\end{tabular}

Most of the respondents (44.17\%) stayed in the hospital less than or equal to 1 day (Table-II), $39.88 \%$ stayed for 2 to 4 days and $1.23 \%$ stayed for more than 10 days. The range of hospital stay was between 6 hours to 15 days. About 99\% of the respondents improved and discharged and 1.23 were dead (Fig. 3).

\section{Discussion:}

During the present study period the total admission in the DMCH were 4,601 and 163 cases were found with retained placenta. So the incidence of RP was $3.54 \%$ of total admission. During this period the number of vaginal deliveries in this Hospital was 1,506 and RP developed in 23 cases. So the Hospital incidence was $1.53 \%$. Incidence of RP at DMCH was found to be $2.90 \%$ of total admission $(9,078)$ in 2002. ${ }^{13}$ In Holiday Internet Edition (5 January, 2003), among pregnancy-related complications the incidence of RP was reported to be $5 \%$ in Bangladesh. ${ }^{14}$ A number of sixteen cases of retained placenta out of 820 vaginal delivery $(1.95 \%)$ was found out in a Dhaka citybased hospital. ${ }^{15}$ The mean age of the respondents was 27.19 years with range 18 to 41 years. Out of 163 respondents, 33.74\% were found at the age group of $26-30$ years and $6.74 \%$ 
were found at the age group of $36-40$ years. It is found consistent with the study conducted by Chhabra and Dhorey ${ }^{16}$, where most of the patients were between 22 to 29 years. Similar finding is also obtained in case of mean age distribution in this study as well as in the study conducted by Titiz. ${ }^{17}$ Regarding the socioeconomic conditions of the families $71.17 \%$ families had monthly income less than Taka $3,000 /$ - and $4.29 \%$ families had monthly income more than Taka 6,000/-. The low income group delay to take decisions to transfer the patient in hospital due to lack of money. So timely interference is deferred and risk of the patient is increased. The aforementioned study in Kasturba Hospital, India (by Chhabra and Dhorey ${ }^{16}$ ) showed that the risks of retained placenta is potentially life-threatening not only because of retention per se, but because of associated haemorrhage and infection as well as complications related to its removal. These risks are increased in women in poor social circumstances due to pre-existing malnutrition, anaemia and unsupervised home deliveries. Among the respondents 55.83\% were of para 2 or 3 , which is consistent with the findings of Chhabra and Dhorey ${ }^{16}$. Most of the deliveries i.e. $81.60 \%$ were conducted at home by the Dai (female birth attendant) or relatives, $14.29 \%$ by doctors at $\mathrm{DMCH}$ and $4.29 \%$ by medical persons at clinics or hospitals outside. Two other studies showed that the incidence of home delivery and hospital delivery were $92.87 \%$ and $2.86 \%$ by Chhabra and Dhorey ${ }^{16}$ and $68.75 \%$ and $31.25 \%$ by Hyder ${ }^{15}$ respectively. These findings are inconsistent with the findings of the present study. Regarding the interval between hospital admission and development of RP it was found that most of the respondents, $61.96 \%$ were admitted between 2 to 6 hours after developing retained placenta which is consistent with the findings of Chhabra and Dhorey ${ }^{16}$. Regarding the past relevant history among the study respondents, $19.63 \%$ of the respondents had MR, $17.79 \%$ had D \& C, $4.29 \%$ had manual removal of RP and $1.84 \%$ had caesarian section in the past. $23.92 \%$ respondents had some predisposing factors of retained placenta. A retrospective study by van Beekhuizen et al. ${ }^{21}$ showed that the recurrence of RP was $32 \%$ while placenta accreta and a history of multiple RPs appeared to pre-dispose to recurrence. Another study by Tandberg et al. ${ }^{18}$ showed that $16 \%$ had experienced retained placenta before. Chhabra and Dhorey ${ }^{16}$ showed $16.9 \%$ women had previous uterine surgery and $1014.1 \%$ had a RP in the past. Findings showed clinical presentations of $49.07 \%$ were shock with $\mathrm{PPH}$ and $1.23 \%$ presented shock without $\mathrm{PPH}$. So retained placenta not only causes haemorrhagic shock it can also causes shock merely by its presence. In the study of Chhabra and Dhorey ${ }^{16}$ showed 26 (36.61\%) women had come in state of severe shock. Associated complications (Fig. 5) with retained placenta were perineal tear (4.29\%), sepsis (3.68\%) and vaginal tear, cervical tear and uterine prolapse $(1.80 \%)$, acute inversion of uterus $(1.23 \%)$. Retained Placenta itself causes PPH and associated genital tract injury causes further PPH which adversely affect the condition of the patient. Above data reflects the mismanagement of labour in all stages by unskilled person. Regarding management, $96.93 \%$ of the respondents needed manual removal of placenta. This is inconsistent with the study conducted by Tandberg et al. ${ }^{18}$ and Hyder $^{15}$, in which they found incidence to be $0.6 \%$ and $81.25 \%$ respectively. These are inconsistent with $96.93 \%$ of the present study and this may be due to different cause of the retained placenta. In this study, 124 (76.07\%) received blood transfusion which greatly differs from the findings of Titiz et al. ${ }^{17}$ and Tandberg et al. ${ }^{18}$ which were $11.40 \%$ and $10 \%$ respectively. This may be due to the fact that pregnant women of our country suffer more from anaemia. Need of blood was more than the amount transfused but patient could not afford due to lack of money, donors and also blood in blood bank. Causes of retained placenta in this study varied with that of Hyder ${ }^{15}$ i.e. $52.76 \%$ vs $37.5 \%$ were due to morbid adhesion and $38.65 \%$ vs $62.5 \%$ were due to uterine inertia respectively. All the morbid adhesions were partial and $96.51 \%$ were placenta accreta. The ACOG Committee opinion shows that women who have had two or more caesarean deliveries with anterior or central placenta 
praevia had nearly a $40 \%$ risk of developing placenta accreta ${ }^{19}$. Another study by Makhseed and Moussa, ${ }^{20}$ showed that the rate of placenta accreta was 98 per 1,000,000 deliveries. About $98.77 \%$ of the respondents improved and discharged and $2(1.23 \%)$ were dead due to irreversible shock. The morbidity can not be detected due to lack of follow up and also beyond the scope of the present study. The aforementioned study in Kasturba Hospital, India by Chhabra and Dhorey ${ }^{16}$ showed that the maternal mortality was $5.6 \%$. The study done by Makhseed and Moussa ${ }^{20}$ showed the maternal death rate was $6.25 \%$ in placenta accreta cases. These inconsistencies with the present study may be due to early arrival of the patients into the hospital with less complications and prompt management.

\section{Conclusions:}

The retained placenta is an obstetric emergency. It occurs in majority of women having home delivery. Uterine inertia and morbid adhesion are found to be the major causes of retained placenta. Mismanagement of $3^{\text {rd }}$ stage of labour is one of the major causes of uterine inertia leading to postpartum haemorrahage and retained placenta. Identification of the risk factors for developing retained placenta during ANC and properly conducted labour can reduce the frequency of $\mathrm{RP}$ cases and thus also reduce the burden upon the health facilities (primary, secondary and tertiary level hospitals). Immediate transfer of $\mathrm{RP}$ cases to a health centre where blood transfusion and operative facilities are available can reduce the maternal mortality due to RP and its consequences. More studies on this field are needed to formulate the prevention and management of RP cases.

\section{References:}

1. All Africa.com. No more tears over retained placenta: new vision (Kampala), News. January 15, 2002 (Weeks AD. The Reained Placenta. Afr Health Sci. 2001; 36-41.

2. DeCherney AH, Nathan L. Current obstetric \& gynecologic diagnosis and treatment, $9^{\text {th }}$ ed. 2002. 54-56, 163-172
3. Hayman RG, Arulkumaran S, Steer PJ. Uterine Compression Sutures: Surgical Management of Postpartum Haemorrhage. Obstet Gynaecol. 2002; 99: 502-6.

4. Akhtar S, et al. Use of condom to control massive postpartum haemorrhage. Medscape General Medicine. 2003.

5. BIRPERHT. Bangladesh Institute of Research for Promotion of Essential and Reproductive Health and Technologies. Report on baseline survey for assessment of EOC services in Bangladesh; 1995.

6. Safe Motherhood News Letter, Issue 2, June 2002.

7. Family and Community Health, WHO, South African Region.

8. Holland and Brew. Manual of obstetrics, $15^{\text {th }}$ ed. 1991: 236-241,493-499

9. Combs CA, Laros RK. Prologned third stage of labor: morbidity and risk factors. Obstet Gynecol. 1991; $77: 863-7$.

10. Health \& Demographic Survey (HDS), 2004.

11. Bangladesh Maternal Mortality Survey, 2001.

12. HNPSP Implementation Plan, Part: I \& II.

13. Statistics of Department of Obstetrics \& Gynaecology, year 2002, Dhaka Medical College Hospital, Dhaka.

14. The Holiday, Internet Edition, 5 January, 2003.

15. Hyder Z. Retained placenta. Medical Journal. 1995; 2(1): 18-21.

16. Chhabra S, Dhorey M. Retained Placenta continues to be fatal but frequency can be reduced. J Obstet Gynaecol. 2002; 22(6): 630-3.

17. Titiz H, Wallace A, Voaklander DC. Manual removal of the placenta: a case control study. Aust NZ J Obstet Gynaecol. 2001; 41(1): 41-4.

18. Tandberg A, Albrechtsen S, Iversen OE. Manual removal of placenta. Acta Obstet Gynecol Scand. 1999; 78: 33-6.

19. Placenta Accreta. ACOG Committee Opinion No. 266. January 2002.

20. Makhseed M, Moussa MA. The outcome of placenta accreta in Kuwait (1981-1993). Int J Obstet Gynaecol. 1995; 50(2) : 139-44.

21. van Beckhuizen HJ, Vierhout ME. Risk of recurrence of retained placenta. [Article in Dutch] [Abstract]. Ned Tijdschr Geneeskd. 1994; 138(43): 2149-52. 